\title{
Rockfall vulnerability assessment for reinforced concrete buildings
}

\author{
O. Mavrouli and J. Corominas \\ Technical University of Catalonia, Barcelona, Spain
}

Received: 11 June 2010 - Revised: 1 September 2010 - Accepted: 16 September 2010 - Published: 6 October 2010

\begin{abstract}
The vulnerability of buildings to the impact of rockfalls is a topic that has recently attracted increasing attention in the scientific literature. The quantification of the vulnerability, when based on empirical or heuristic approaches requires data recorded from historical rockfalls, which are not always available. This is the reason why appropriate alternatives are required. The use of analytical and numerical models can be one of them. In this paper, a methodology is proposed for the analytical evaluation of the vulnerability of reinforced concrete buildings. The vulnerability is included in the risk equation by incorporating the uncertainty of the impact location of the rock block and the subsequent damage level. The output is a weighted vulnerability that ranges from 0 to 1 and expresses the potential damage that a rock block causes to a building in function of its velocity and size. The vulnerability is calculated by the sum of the products of the probability of block impact on each element of the building and its associated damage state, the latter expressed in relative recovery cost terms. The probability of exceeding a specific damage state such as non-structural, local, partial, extensive or total collapse is also important for the quantification of risk and to this purpose, several sets of fragility curves for various rock diameters and increasing velocities have been prepared. An example is shown for the case of a simple reinforced concrete building and impact energies from 0 to $4075 \mathrm{~kJ}$.
\end{abstract}

\section{Introduction}

During the last decade an important number of studies has been made on the Quantitative Risk Assessment (QRA) due to rockfalls to enhance the thorough and comprehensive understanding of the risk levels in mountainous urban areas and roads and to support the optimization of risk manage-

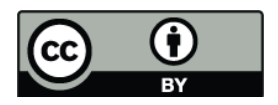

Correspondence to: O. Mavrouli (olga-christina.mavrouli@upc.edu) ment measures (Pierson et al., 1990; Bell and Glade, 2004; Budetta, 2004; Guzzetti et al., 2004; Roberds, 2005; Corominas et al., 2005; Agliardi et al., 2009; Li et al., 2009). When it comes to the evaluation of the rockfall risk, besides the hazard, vulnerability plays a fundamental role. Even for high hazard values, the final risk might result low in case of exposed elements having low vulnerability and vice-versa. Thus the use of a reliable vulnerability index is very important. So far the quantification of vulnerability in front of rockfalls has experienced little progress when compared with that achieved in the field of hazard assessment.

For landslides, Glade (2003) presented explicitly the approaches used for the integration of vulnerability in landslide risk analysis, which vary according to their application scale, structural typology and damage evaluation assumptions.

Heinimann (1999) and Uzielli et al. (2008) attributed a vulnerability value to buildings according to their typology for use at regional scale. Many researchers have also investigated the physical structural vulnerability at local or sitespecific scale. Dai (2002) proposed a general framework for the classification of the physical vulnerability of buildings to landslides, which takes into account their individual characteristics (e.g. type, nature, age) and can be applied at a site-specific or global scale (the latter summing up the sitespecific results). The methodology requires the statistical analysis of past event data. Agliardi et al. (2009) proposed a rockfall vulnerability function based on observations and back analysis of the damage of individual buildings during the Fiumelatte event.

The methodologies and approaches mentioned above implicitly assume that landslide events of similar magnitude produce the same level of damage. However, this assumption is not strictly true because, for instance, the damage caused by a rockfall of a given magnitude ("magnitude" from now on is used to describe the volume of the rock block) depends on both the location and the energy of the impact, which may change from one event to the other. For instance, for a rock block moving with a certain intensity ("intensity" from now on is used to describe the kinetic energy of the rock block)

Published by Copernicus Publications on behalf of the European Geosciences Union. 
one may expect significant damage at a building if a key structural element is struck and broken by the impact, while damage may be low and local if a non-structural element is affected.

The main objectives for this work have been: (a) the definition of a vulnerability index that can be used as an input into the risk equation, (b) the development of a step-by step procedure for the quantification of the vulnerability that does not require a record of historical rockfall event data, and (c) the development of a methodology for the generation of rockfall fragility curves.

To this aim, this paper provides a step-by-step analytical methodology for the quantification of the physical vulnerability of reinforced concrete (from now on RC) structures which are situated in the rockfall path and struck by individual rock blocks. The vulnerability defined here concords with the vulnerability definition by UNDRO (1991): the degree of loss to a given element at risk or set of such elements resulting from the occurrence of a natural phenomenon of a given magnitude and expressed on a scale from 0 (no damage) to 1 (total loss). Additionally, the uncertainty which is associated with the location of the impact and the resultant damage is incorporated into the vulnerability using a weighted vulnerability index, in which the total potential damage is determined by combining the probability of encounter $P_{\mathrm{e}, k}$ of the rock block with one or more building's structural or non-structural elements and its associated damage state.

Alternatively, the vulnerability may be expressed using fragility curves diagrams. Fragility curves provide a graphic expression of the probability of exceeding a given damage state under a certain hazardous event. They are very useful when the performance of a building under a damaging event is governed by important uncertainties, thus the potential extent of the damage should be evaluated for different magnitudes (or intensities) of the hazardous event using probabilistic terms. To this purpose representative damage states which are associated with the consequences (i.e. financial cost, people safety etc.) should be defined. Fragility curves might be empirical, judgmental or analytical, depending on how the damage state is evaluated for a given magnitude (or intensity) of the hazardous event.

The vulnerability of a structure to rockfalls expresses the expected loss due to the impact of a rock block of a certain magnitude and velocity. To evaluate it in quantitative terms, a function has to be defined that correlates both parameters with the probability of exceeding a certain response (i.e. damage) level, also accounting for the uncertainty of the impact location. This function may be described using sets of fragility curves. Based on this, in this paper, fragility curves will be generated for a range of rock diameters in function of the rock velocity taking into account the uncertainty of the impact location.

The methodology that is described in this paper implements a procedure developed by Mavrouli and Corominas
(2010) for the analytical evaluation of the structural performance of RC buildings which are subjected to rockfall impacts.

Furthermore, in order to provide a quantitative evaluation of the vulnerability in money terms, the amount of damage that the block impact causes to the building is correlated with the recovery cost of the latter.

\subsection{Effects of rockfall impacts on structures}

As observed from historical rockfalls, the damage extent presents a large dispersion from slight non-structural damage to total collapse, according to the building characteristics, the rock's size and velocity. Here some selected cases of rock impacts to buildings that cover a full range of types and states of damage are presented.

Non-structural damage, e.g. destruction of infill walls, doors and windows is often reported as in the case of rockfalls in Bíldudalur, Iceland (Bell and Glade, 2004). Corominas et al. (2005) have reported several rockfall events in Andorra, among which one in 1997 when a block of $25 \mathrm{~m}^{3}$ volume penetrated the slabs of a residence building, ending down to its basement. The building stood without further extensive damage. Serious structural damage occurred at the event of Segovia, Spain, in 2004, when boulders fell on the roof of the Fuencisla Sanctuary (Romana, 2009). Very interesting observations of damage could be carried out at the Fiumelatte rockfall of 2004 in Italy (Agliardi et al., 2009). In this event a large number of blocks were released from a cliff above the village causing a variety of damage at buildings, from slight damage to total loss of a structure. For instance, roof damage was caused by a block of $8 \mathrm{~m}^{3} \mathrm{im}$ pacting on the corner of a building while extensive damage was observed in two multiple storey buildings by a block of $96 \mathrm{~m}^{3}$. Recent devastating rockfall events resulting in utterly flattened houses were reported by the media for the rockfalls of Yemen in 2005 and Cairo in 2008 involving massive failure of rock blocks fragments of several hundreds of cubic meters. Additionally, serious damages have been registered for various events at Hong Kong (Chau et al., 2002), Canada (Evans and Hungr, 1993) and United States (Wieczorek and Snyder, 2004 and Castleton, 2009).

The amount of damage in the afore-mentioned cases depends on the impact location and the importance of the impacted members for the stability of the building. As for the location, for RC buildings situated at the foot of rocky slopes four major impact locations can be distinguished: impact and penetration of the roof; impact and damage of columns and/or beams; penetration of slabs; and impact and damage of infill walls and openings (including doors, windows etc.). Considering the importance of the impacted members, loss can be classified depending on the type of the affected elements as damage of: (i) primary structural elements (e.g. columns and beams for RC); (ii) secondary structural elements (e.g. slabs); (iii) primary non-structural elements 

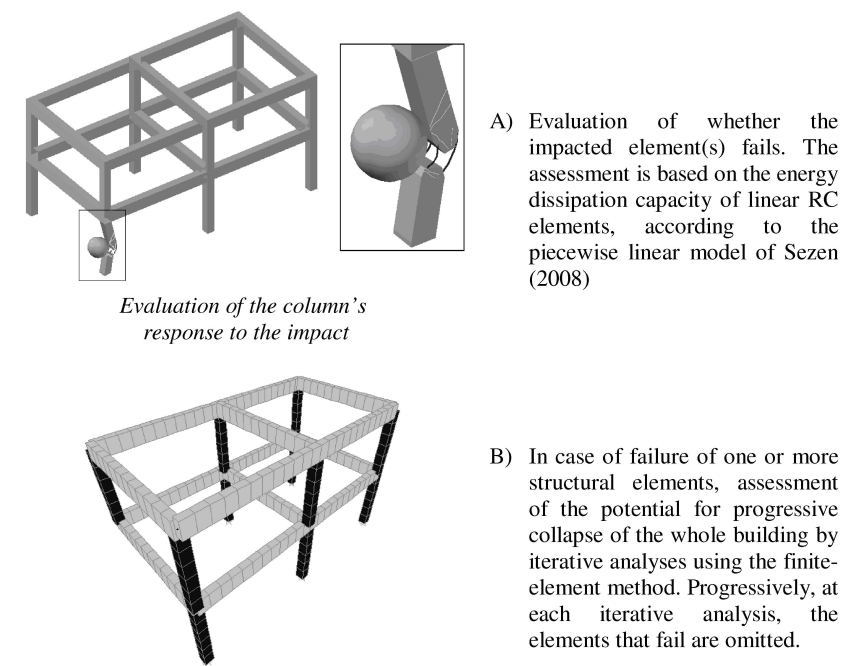

Finite-element model for the progressive collapse analysis

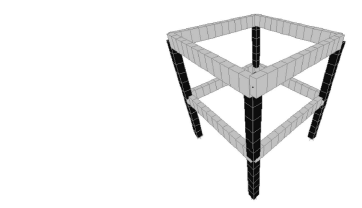

Finite-element model at the end of the progressive collapse analysis

Fig. 1. The three main steps of the methodology by Mavrouli and Corominas (2010) for the quantitative evaluation of structural damage.

(e.g. infill walls and ceilings); and (iv) furniture and electri$\mathrm{cal} /$ mechanical equipment.

The only impact location that might lead to instability of the whole structure is that affecting columns and/or beams. Instead, impacts on secondary structural elements are not crucial for the stability of the load-bearing system; however their damage could have side effects like the blow of debris resulting in further damage and injuries. The same applies to primary non-structural elements while damage of electri$\mathrm{cal} /$ mechanical equipment though repairable, may be costly as well.

Taking this into account, in the approach proposed here the response of the primary structural elements will define the vulnerability of the building. According to what has been observed for such impacts on buildings (Allen and Schrlever, 1972), the damage that is initially produced at the affected columns is localized at the vicinity of the impact. Depending on the rock motion parameters and the column's resistance, the latter may loose its load-bearing ability. This change to the boundary conditions of the structure may initiate a progressive collapse leading to high damage disproportionate to the original cause.

Four damage states are thus proposed here: (1) nonstructural damage: the impact causes the destruction of pri- mary non-structural elements; (2) local damage: the impact causes the destruction of primary structural elements without further significant damage; (2) partial collapse: the impact causes the destruction of primary structural elements, whose loss initiates a progressive collapse of the structural frame leading to loss up to $30 \%$ of the building; (3) extensive to total collapse: the impact causes the destruction of primary structural elements whose loss initiates a progressive collapse of the structural frame leading to physical loss greater than $30 \%$ of the building.

\subsection{Analytical evaluation of the damage index DI and of the relative recovery cost $\mathrm{RRC}$}

Before estimating vulnerability, it is first of all necessary to evaluate the amount of damage produced by the block impact. This has been carried out analytically for the case of $\mathrm{RC}$ buildings that are situated at the bottom of a slope and are impacted at their basement.

The rockfall intensity parameter is the kinetic energy $E_{k}$ of the rock block as calculated by:

$E_{k}=\frac{1}{2} m v^{2}$

where,

$m$ : rock mass,

$v$ : rock velocity.

The response of a building to a rock impact depends on both the location and intensity of the strike. Impacts on nonstructural elements are not crucial for the structural stability, while the failure of primary structural element(s) might initiate a progressive collapse mechanism.

The amount of structural damage, may be expressed by a damage index DI for a given impact location and kinetic energy $E_{k}$. The proposed DI is given by Eq. (2) as the ratio of the number of primary structural elements that fail after the impact to the original number of elements. The calculation of the number of standing elements and the DI is made using a a step-by-step analytical procedure that was developed by Mavrouli and Corominas (2010) for the assessment of the performance of buildings which are impacted by rockfalls.

$\mathrm{DI}=\frac{\text { number of primary structural elements that fail }}{\text { total number of primary structural elements }}$

A schematic representation of the followed steps is shown in Fig. 1.

The DI has to be calculated for each building typology, in function of its load-bearing system as well as the block's trajectory and $E_{k}$.

The non-structural damage refers to the destruction of an infill wall due to a rock impact and it is assumed when the mass of the rock exceeds a certain threshold (here, this threshold is $250 \mathrm{~kg}$ ).

The risk is usually defined as the expected annual loss to the property, as often requested by administrative authorities 
and other interested parties. The physical structural damage (expressed by the DI) and the non-structural damage that are calculated as described in the previous paragraphs, provide fundamental information that is necessary for the estimation of the potential economic loss due to rockfalls. However, in order to assess the latter there is a need to interpret the physical, structural and non-structural damage, into relative economical cost. The interpretation is made based on the DI as it provides a clear indication of the potential structural damage extent. Additionally, an index that describes the economic loss is needed as an output, as well as a function that associates the latter and the DI. The financial loss is expressed here using the relative repair cost RRC, which is given by:

$\mathrm{RRC}=\frac{\text { recovery cost }}{\text { value of building }} \leq 1$

The RRC, although referred to the monetary repair costs, is not a cost itself, but a parameter that is used to scale the building cost for the quantification of risk (e.g. expected loss).

For converting the DI (physical) into RRC (monetary) terms, the association between them is also essential. To this purpose, the DI values have to be grouped into different damage states of the building. The correlation functions between the DI and the RRC are established for each state separately, according to the building characteristics (dimensions, materials, etc). In that respect, the repair cost of an element or a building may be higher than its initial value as it includes demolition and/or retrofitting expenses. As a result, for not extensive collapse, the RRC is proportional to the DI even though it is usually higher than the latter. For extensive collapse, the repair might result technically unfeasible or more expensive than the complete reconstruction of the building. In those cases, high values of the DI correspond to RRC equal to 1 . The correlation functions can be developed using methodologies similar to those used for the earthquake vulnerability which may be adapted for landslides. This will be shown in the following sections with an example.

\subsection{Estimating vulnerability}

\subsection{Vulnerability index}

The proposed risk equation for an exposed building is:

$R(P)=\sum_{i=1}^{i} \sum_{j=1}^{j}\left[P\left(R_{i}\right) x P\left(E_{j}: R_{i}\right) x P(S: \mathrm{T}) x V\left(R_{i j}\right)\right] x C$

where,

$R(P)$ : expected annual loss to the property due to rockfall (e.g. $€ / \mathrm{yr}$ ),

$P\left(R_{i}\right)$ : annual probability of occurrence of a rockfall with a magnitude " $i$ ",

$P\left(E_{j}: R_{i}\right)$ : probability of a rockfall with a kinetic energy (intensity) reaching the critical section that marks the developed area. The latter is calculated as a function of the magnitude (volume) " $i$ " and the velocity " $j$ ",

$P(S: T)$ : probability of the building being on the block's trajectory (calculated as the ratio of the building's width to the critical section's width),

$V\left(R_{i j}\right)$ : vulnerability of the building for a rockfall of magnitude " $i$ " and velocity " $j$ ",

$C$ : value of the building.

The terms $P\left(R_{i}\right)$ and $P\left(E_{j}: R_{i}\right)$ represent the hazard, $P(S: T)$ the exposure and $V\left(R_{i j}\right)$ the vulnerability.

To take the uncertainty of the impact location into account the vulnerability is calculated as the sum of the products of the probability of encounter of the rock block with a structural or non-structural element and the associated RRC. It is given by Eq. (5):

$V\left(R_{i j}\right)=\sum_{k=1}^{k}\left(P_{\mathrm{e}, k} x \mathrm{RRC}_{k}\right) \leq 1$

where,

$V\left(R_{i j}\right)$ : vulnerability for a rock bloc with a magnitude " $i$ " and velocity " $j "$,

$P_{\mathrm{e}, k}$ : encounter probability of a rock with a possible structural and non-structural element of the building " $k$ " that may be struck by a rock block of magnitude " $i$ ",

$\mathrm{RRC}_{k}$ : relative recovery cost that corresponds to the struck of a possible structural and non-structural element of the building " $k$ " by a rock block of magnitude " $i$ " and velocity " $j "$,

$P_{\mathrm{e}, k}$ is calculated for all the possible structural and non-structural elements that may be struck by a rock block. For every rockfall magnitude a different $P_{\mathrm{e}, k}$ is attributed to each structural element. For a block magnitude with a given velocity and path there will be a DI and an associated RRC. Thus, using Eq. (5) the vulnerability is calculated in function of the diameter $d$ and velocity $v$ of the block.

The value 0 of the vulnerability expresses zero potential damage and the value 1 certain total collapse (total loss) of the building.

The collapse of walls caused by the damage to columns (and consequent displacements) is partly taken into account through the RRC, which refers to the total value of the building and not only of its structural system. The case of damage to columns without a direct block impact to a wall is a very low probability case which affects only those blocks with a diameter smaller than the column width and thus was not considered here.

The probability of occurrence of a rock magnitude, velocity and path are not intrinsic to the building and thus not 


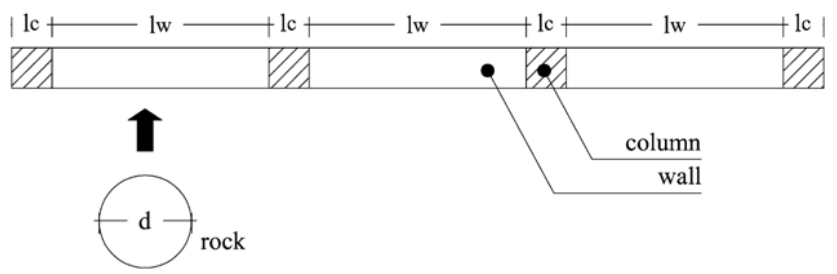

Fig. 2. Set-up of a reinforced concrete building's façade and rock block.

considered into the vulnerability. Instead they form part of the rockfall hazard.

All possible impact locations that may lead to different states of damage must be determined. Here, the assumption of a rock moving towards a building's façade with a path width equal to the width of the latter is made. For RC structures, façades are composed by load-bearing columns and beams as well as infill walls. When a rock impacts both a wall and a column, full transmission of the rock's $E_{k}$ to the latter is considered from the safety side, given its importance for the structural stability over the local wall damage.

The set-up of an indicative façade is illustrated in Fig. 2. Ideally, columns and walls are typical and symmetrical.

In order to calculate the $P_{\mathrm{e}, k}$ with any column, Eq. (6) is used. It was initially proposed by Brauner et al. (2005) for rock impacts onto trees and here it was adapted to columns and walls.

$P_{\mathrm{ec}}=\min \left(\frac{l_{\mathrm{c}}+d}{l_{\mathrm{c}}+l_{\mathrm{w}}}, 1\right)=f(d)$

where,

$P_{\mathrm{ec}}$ : encounter probability of a rock block with any column,

$l_{\mathrm{c}}:$ column width,

$l_{\mathrm{w}}:$ wall width,

$d$ : rock block diameter.

The encounter probability with a wall is calculated as:

$P_{\mathrm{ew}}=\min \left(\frac{l_{\mathrm{w}}+d}{l_{\mathrm{c}}+l_{\mathrm{w}}}, 1\right)=f(d)$

where,

$P_{\text {ew }}$ : encounter probability of a wall.

For more complex façades, $\mathrm{Eq}(\mathrm{s})$. (6 and 7) should be modified accordingly.

An example of how RRC is calculated is given in a later section.

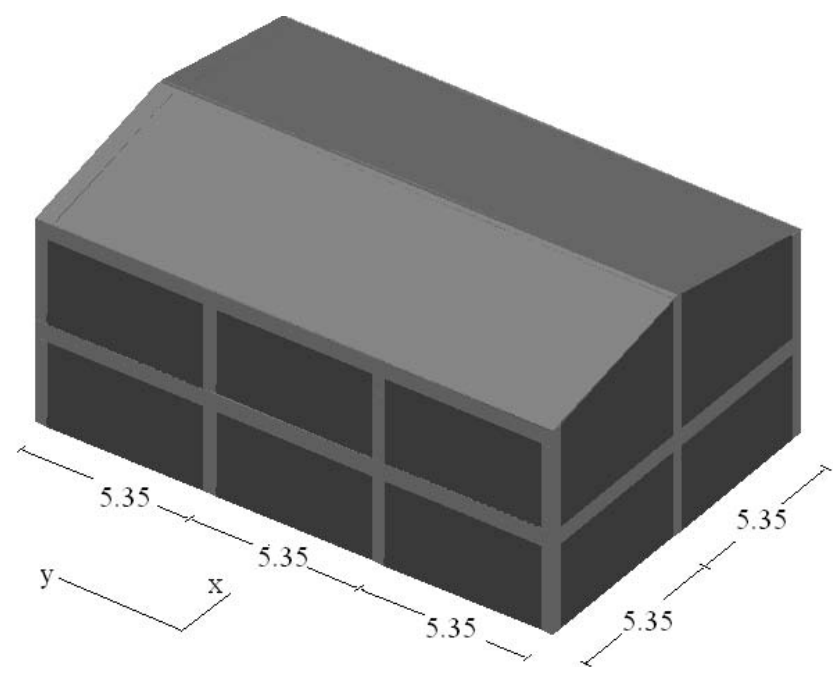

Fig. 3. The building geometry (dimensions in $\mathrm{m}$ ).

\subsection{Fragility curves}

To estimate the vulnerability for a range of block magnitudes and intensities, fragility curves may be developed. In the following section, sets of fragility curves are presented for intensities ranging from 0.5 to $8 \mathrm{~m} / \mathrm{s}$ and different block magnitudes. The fragility curves are generated based on analytical results using the methodology by Mavrouli and Corominas (2010) for the evaluation of the response of the structure. The latter is classified into the same damage states as those for the correlation of the DI with the RRC.

\subsection{Application to a simple reinforced concrete building}

The proposed methodology can be applied to the case of buildings exposed to fragmental rockfalls i.e., rockfall events composed of one or a few rock blocks moving with independent trajectories. In the presented example, only the consequences of the impact of a single block are analyzed. Block impact intensities used in the example correspond to velocities ranging from 0.5 to $8 \mathrm{~m} / \mathrm{s}$ and block diameters from 0.20 to $4.6 \mathrm{~m}$. The maximum $E_{k}$ reached by the block is $4075 \mathrm{~kJ}$ $(d=4.60 \mathrm{~m}, v=8 \mathrm{~m} / \mathrm{s})$.

The vulnerability index is calculated for the case of a simple RC building. It has a basement and two floors with 2 frames at $\mathrm{x}$-direction and 3 at $\mathrm{y}$-direction. Columns have a section of $35 \times 35 \mathrm{~cm}$ and beams of $25 \times 60 \mathrm{~cm}$. Columns have longitudinal reinforcement $1.46 \%$ and beam $1.04 \%$. The shear reinforcement is $0.16 \%$ and $0.13 \%$ respectively. The materials are for concrete $\mathrm{C} 20$ (compressive strength $20 \mathrm{MPa}$ ) and for steel S500s (tensile strength $500 \mathrm{MPa}$ ). Figure 3 illustrates the geometry of the building.

The façade $\mathrm{x}$ is exposed to the impact of a single rock block. For the risk evaluation all trajectories (perpendicular and oblique to the façade) have to be considered, but for simplification purposes after the impact, the block is considered to move perpendicularly to the façade. This consideration 


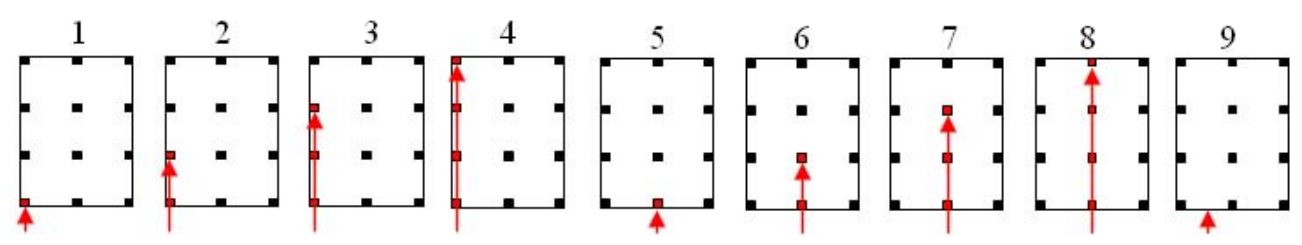

Fig. 4. The 9 considered scenarios (columns in the path of the red arrows have failed).

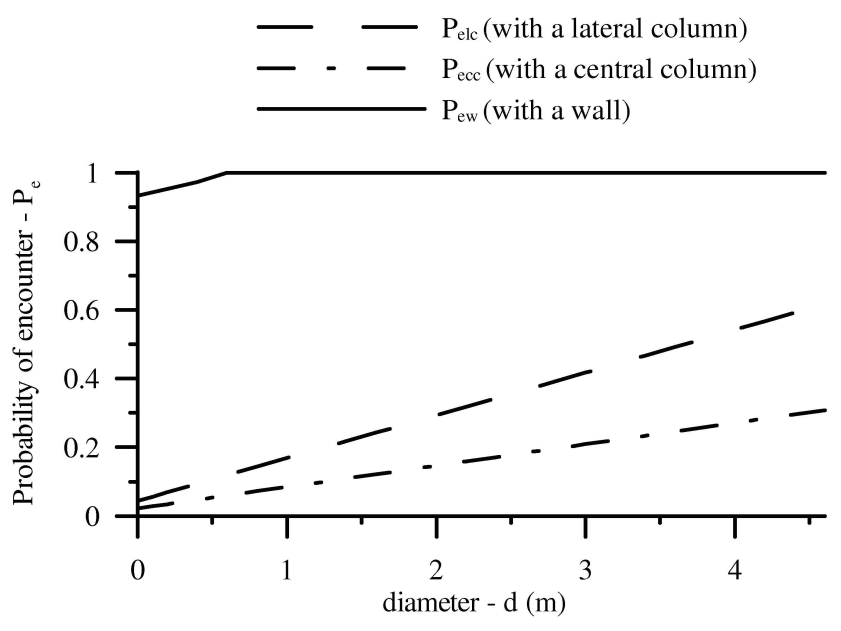

Fig. 5. Probability of encounter with structural and non-structural elements.

is based on the fact that even though an oblique impact with the same kinetic energy has higher probability of hitting a primary structural element, the probability of building collapse is smaller than in the case of the perpendicular trajectories (see Mavrouli and Corominas, 2010). So the perpendicular scenarios were selected to be analysed as the most unfavourable.

For the evaluation of the potential structural damage, four levels of $E_{k}$ and three impact locations are considered. The selected $E_{k}$ levels are those capable to cause the destruction of one, two, three or four columns. For this particular building the $E_{k}$ thresholds are $14,28,42,56 \mathrm{~kJ}$ respectively. The description of the methodology for the calculation of these thresholds is beyond the scope of this paper and it is explained in detail at Mavrouli and Corominas (2010). The three impact locations are: a lateral column, a central column or an infill wall. Under these assumptions, for the damage of $1,2,3$, or 4 central or lateral columns, the possible consequence scenarios are nine (Fig. 4). Each scenario will result in a specific DI.

The first step for the calculation of the vulnerability index is the evaluation of the $P_{\mathrm{e}, k}$ for every impact location. For this geometry, the probability of encounter with a lateral column $P_{\text {elc }}$ is the double of the probability of encounter with a central column $P_{\text {ecc }}$. It is:

$P_{\mathrm{elc}}=\min \left(\frac{2}{3} \frac{l_{\mathrm{c}}+d}{l_{\mathrm{c}}+l_{\mathrm{w}}}, 1\right)$

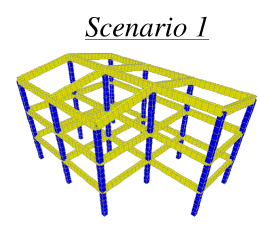

$\mathrm{DI}=0.11$

Scenario 4

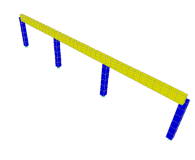

$\mathrm{DI}=0.91$

Scenario 7

total colapse

$\mathrm{DI}=1.00$

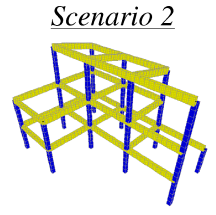

$\mathrm{DI}=0.70$

Scenario 5

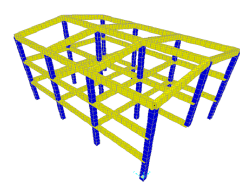

total colapse

Scenario 3

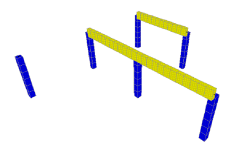

$\mathrm{DI}=0.89$

Scenario 6

$\mathrm{DI}=1.00$

$\begin{array}{ccc}\text { Scenario } 7 & \underline{\text { Scenario } 8} & \text { Scenario } 9 \\ \text { total colapse } & \text { total colapse } \\ \mathrm{DI}=1.00 & \mathrm{DI}=1.00 \quad \begin{array}{c}\mathrm{DI}=0.00 \\ \text { local non-structural } \\ \text { damage }\end{array}\end{array}$

Fig. 6. Remaining undamaged structure and structural damage index DI that results for every impact scenario.

$P_{\mathrm{ecc}}=\min \left(\frac{1}{3} \frac{l_{\mathrm{c}}+d}{l_{\mathrm{c}}+l_{\mathrm{w}}}, 1\right)$
$P_{\mathrm{ew}}=\min \left(\frac{l_{\mathrm{w}}+d}{l_{\mathrm{c}}+l_{\mathrm{w}}}, 1\right)$

where,

$P_{\text {elc }}$ : encounter probability of a rock with a lateral column,

$P_{\text {ecc }}$ : encounter probability of a rock with a central column,

$P_{\text {ew }}$ : encounter probability of a rock with a wall only.

The results are presented in Fig. 5 for increasing diameters of the rock block. 
Table 1. Damage states.

\begin{tabular}{llll}
\hline $\begin{array}{l}\text { Damage } \\
\text { Level }\end{array}$ & $E_{k}(\mathrm{~kJ})$ & Thresholds & $\begin{array}{l}\text { Damage } \\
\text { Description }\end{array}$ \\
\hline 1 & $E_{k} \leq 14 \mathrm{~kJ}$ & $m \geq 250 \mathrm{~kg}$ & Non-structural \\
2 & $14 \mathrm{~kJ}<E_{k} \leq 28 \mathrm{~kJ}$ & $0.0<\mathrm{DI}<0.05$ & Local structural \\
3 & $14 \mathrm{~kJ}<E_{k} \leq 28 \mathrm{~kJ}$ & $0.05<\mathrm{DI}<0.3$ & Partial collapse \\
4 & $E_{k}>28 \mathrm{~kJ}$ & $\mathrm{DI} \geq 0.3$ & $\begin{array}{l}\text { Extensive or } \\
\text { total collapse }\end{array}$ \\
\hline
\end{tabular}

For the calculation of the DI for each of the three impact locations and for the four energy levels, the structural response of the building to a rock hit is evaluated. Figure 6 presents for each scenario the final state (the undamaged part of the building), after performing progressive collapse analyses using the finite-element method, and the correspondent DI.

For scenario 1, with $E_{k}$ between $14 \mathrm{~kJ}$ and $28 \mathrm{~kJ}$, the damage of one lateral column initiates a cascade of failures up to the partial collapse along the building's height. With the same $E_{k}$, in the case of scenario 5 that refers to damage of one central column no further damage but local is caused. For scenario 2 with $E_{k}$ between $28 \mathrm{~kJ}$ and $42 \mathrm{~kJ}$, a progressive failure takes place resulting to damage of more than $30 \%$ of the building. For all the other scenarios with $E_{k}$ higher than $28 \mathrm{~kJ}(3,4,6,7$ and 8), the collapse is extensive up to total. Scenario 9 corresponds to the impact on an infill wall and in this case only non-structural damage is produced.

For the non-structural damage to the walls (scenario 9), failure is roughly considered for a mass greater than $250 \mathrm{~kg}$. The DI is equal to 0 but repair is necessary for the local wall damage.

The structural damage scenarios shown in Fig. 6 are classified into states (Table 1) based on the observation of the results.

To determine the function that correlates the RRC with the DI, we were based on the damage scale of Whitman et al. (1973). These authors, based on a survey of damage for buildings due to earthquake, provided a list of damage states, followed by a subjective description of physical damage and an objective ratio of repair cost to replacement cost, which in this paper corresponds to RRC. Although the damage of a building due to an earthquake is usually affecting a building uniformly while in the case of rockfalls the resultant damage might be only local, what is used here is the information that Whitman et al. (1973) provided on the thresholds of the ratio of repair cost to replacement cost for each damage state, which is believed to have general applicability. Considering the provided ranges, the RRC is evaluated to be $0-0.2$ for local damage, $0.2-0.5$ for partial collapse and 1 for extensive or total collapse. The correlation function between RRC and DI is shown in Fig. 7.

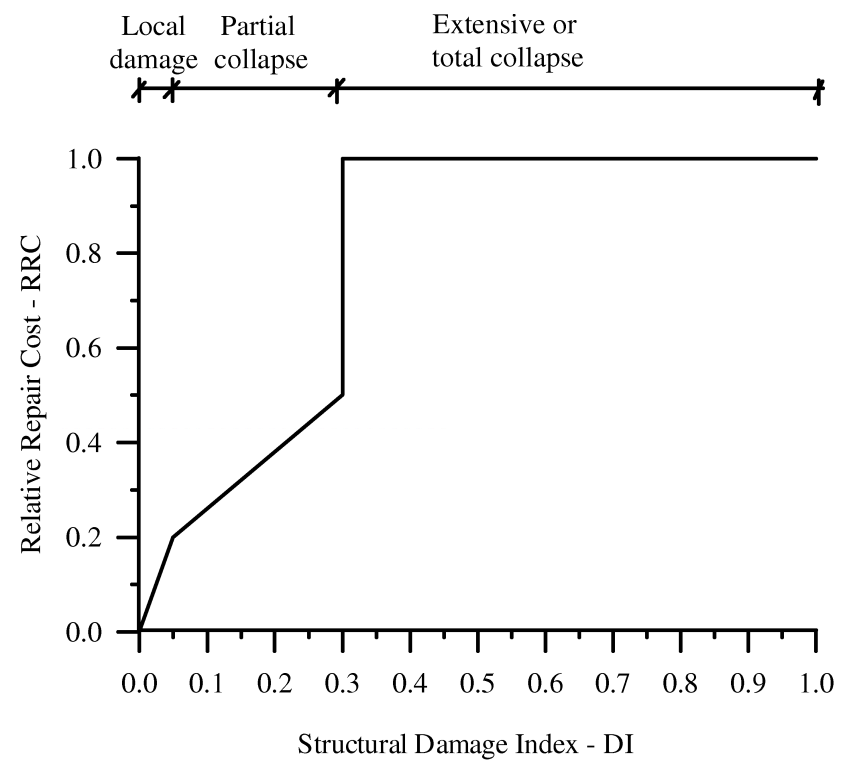

Fig. 7. Correlation of RRC with the DI.

When there is further damage than partial collapse (for values of the DI higher than 0.30), the damage is considered excessive and total reconstruction is preferable than repair, thus the RRC is 1 as in the case of total collapse. The rule of $50 \%$ was selected because of its wide application at similar cases, as for example it is applied by FEMA Guidance No. 4511.61, where "A facility is considered repairable when disaster damages do not exceed $50 \%$ of the cost of replacing a facility to its pre-disaster condition, and it is feasible to repair the facility so that it can perform the function for which it was being used as well as it did immediately prior to the disaster".

For non-structural damage the RRC is taken equal to 0.01 . Equation (5) is transformed into Eq. (11):

$V\left(R_{i j}\right)=P_{\mathrm{elc}} x \mathrm{RRC}_{\mathrm{lc}}+P_{\mathrm{ecc}} x \mathrm{RRC}_{\mathrm{cc}}+P_{\mathrm{ew}} x \mathrm{RRC}_{\mathrm{w}} \leq 1$

where,

$\mathrm{RRC}_{\mathrm{lc}}$ : relative repair cost for impact on a lateral column,

$\mathrm{RRC}_{\mathrm{cc}}$ : relative repair cost for impact on a central column,

$\mathrm{RRC}_{\mathrm{w}}$ : relative repair cost for impact on a wall.

Table 2 shows the results that can be used as input to Eq. (3).

In order to define the possible damage states that may occur for each velocity and diameter, the table is separated into four areas which are distinguished with different colours. Colours change according to the most unfavourable potential damage state. Green stands for no potential damage, yellow for potential non-structural damage (damage state 1), orange for local structural damage or partial collapse (damage 


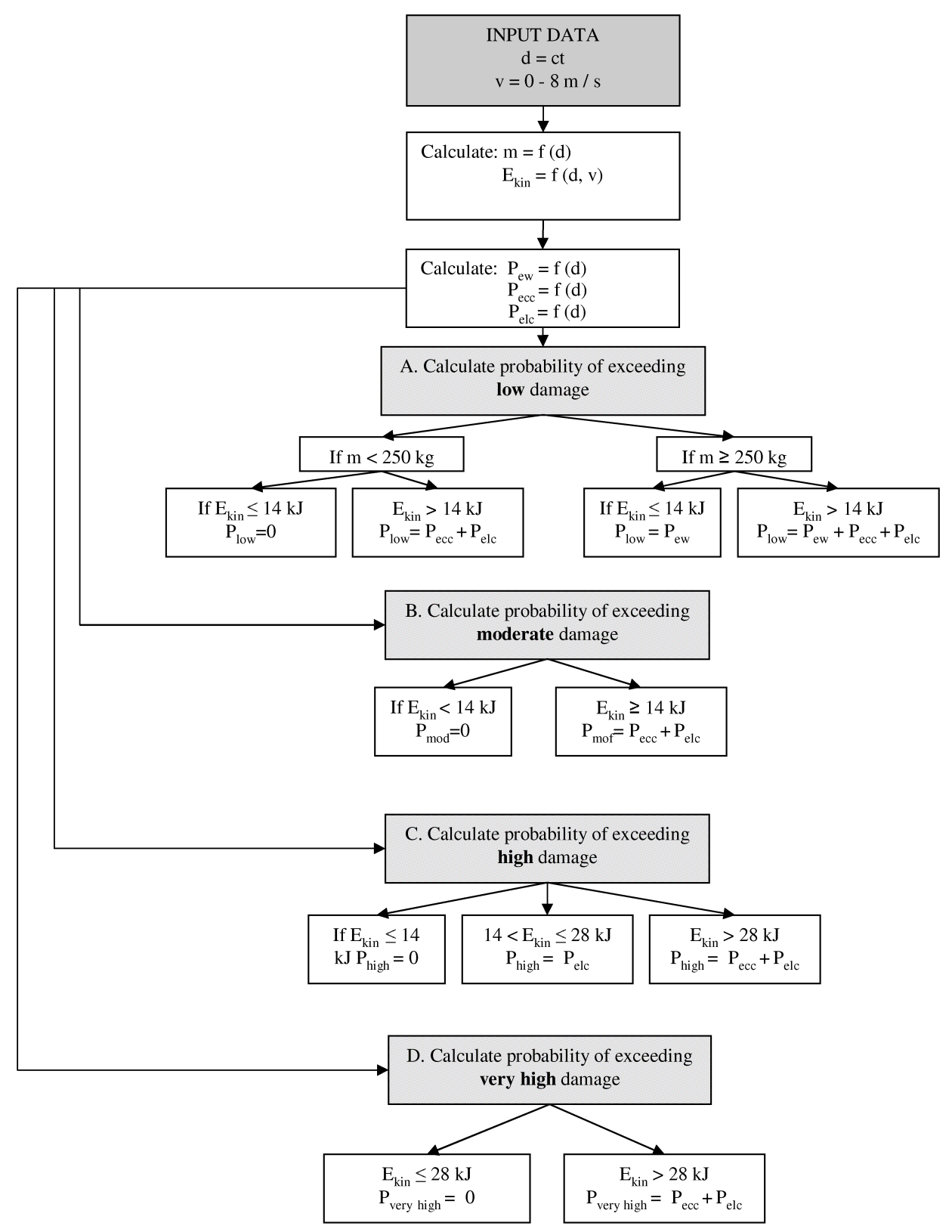

Fig. 8. Algorithm for the calculation of the probability of each damage state.

state 2 or 3, respectively), and red for extensive or total collapse (damage state 4).

The limits between the potential damage states are defined on the basis of the $E_{k}$ thresholds, which depend on the diameter and velocity that are sufficient to cause damage of one or more columns (see Table 1).

Using the same results from the analysis, sets of fragility curves were developed for rock diameters up to $5.0 \mathrm{~m}$ with a step of $0.5 \mathrm{~m}$ and increasing velocities $0.5-8.0 \mathrm{~m} / \mathrm{s}$.

Since structural vulnerability is expressed with respect to the damage state, a similar reference scale as for the vulnerability index is assumed, as shown in Table 3.
The algorithm developed for the calculation of the probability of each damage state is presented in Fig. 8. The results for every rock diameter are shown in Fig. 9.

The results indicate that even for low velocities, low non-structural damage is highly probable, while structural damage (moderate, high and very high damage) has a probability greater than $50 \%$ for $d \geq 2.5 \mathrm{~m}$ and $v>1.5 \mathrm{~m} / \mathrm{s}$. The sufficient velocity to cause moderate, high and very high damage also varies with the rock diameter. For example for $v=1 \mathrm{~m} / \mathrm{s}$, moderate or high damage is caused for $d=2.5 \mathrm{~m}$ and very high for $d=3 \mathrm{~m}$. For the higher velocity $v=2 \mathrm{~m} / \mathrm{s}$ the same thresholds are lower: $d=1.5 \mathrm{~m}$ and $d=2 \mathrm{~m}$, respectively. 

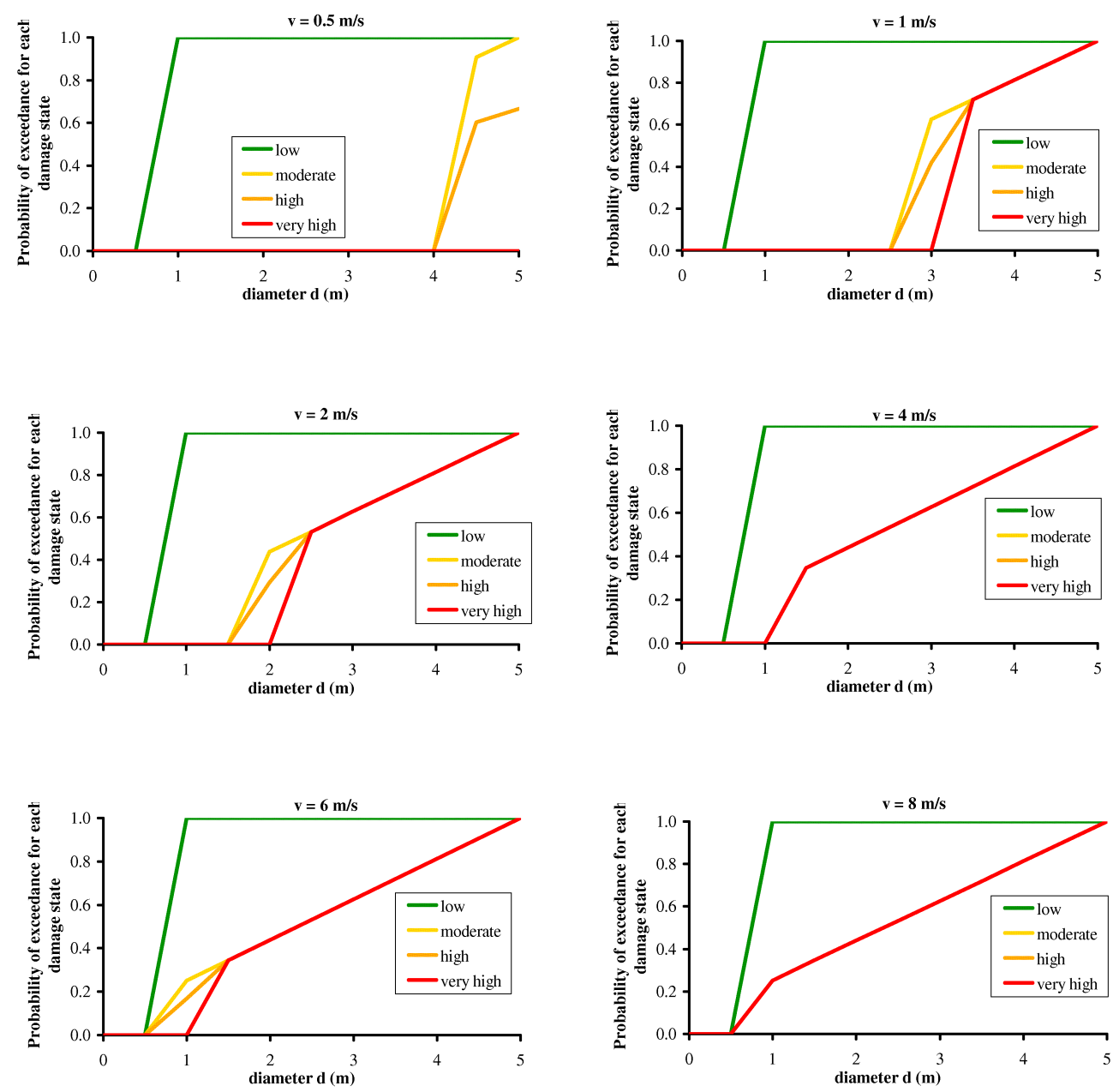

Fig. 9. Fragility curves for different rock velocities.

\section{Discussion and conclusions}

According to the objectives that have been explained at the introduction of this paper, a vulnerability index that is representative of the potential for damage for a building impacted by a fragmented rockfall was defined. This index is in accordance with the most common vulnerability definitions and does not require a record of previous events.

Using the proposed index, the physical vulnerability can be quantified for a given building as a function of the velocity and the size of the block. The index is non-linear, with a range from 0 to 1 . Increasing values of vulnerability indicate increasing potential for higher damage. The expected damage states can be defined as a function of the rock velocity and diameter, based on the corresponding kinetic energy thresholds and the respective analysis results. So for a given diameter and velocity, the possibility of no damage, non-structural damage, local damage or partial collapse and extended or total collapse is indicated.

Alternatively the vulnerability was expressed in probabilistic terms using fragility curve diagrams that indicate the probability of exceedance for each damage state. The usefulness of these diagrams is that they provide a simple measure of the vulnerability for the buildings and of the possible extent of damage for a given event. The additional information that the fragility curves offer over the vulnerability index is that they indicate the critical rock diameters that are sufficient to cause low, moderate, high or very high damage, for different velocities. Additionally, the important effect of the velocity was evaluated. For example for the analysed building, it is indicated that for low velocities (such as $0.5 \mathrm{~m} / \mathrm{s}$ ) high damage is highly improbable, and for high velocities (such as $8 \mathrm{~m} / \mathrm{s}$ ), even rocks of $1 \mathrm{~m}^{3}$ are sufficient to cause very high damage.

The proposed methodology maybe applied at site-specific scale for the calculation of the vulnerability of an individual building, in the case of a single block impact on it. This situation is what might be expected in areas affected by low to moderate rockfall activity. It might be useful, for example, 
Table 2. Vulnerability as a function of rock diameter (or mass) and velocity.

\begin{tabular}{|c|c|c|c|c|c|c|c|c|c|c|c|c|c|c|c|c|c|}
\hline \multirow[t]{2}{*}{$d(\mathrm{~m})$} & \multirow[t]{2}{*}{$m(\mathrm{~kg})$} & \multicolumn{16}{|c|}{$v(\mathrm{~m} / \mathrm{s})$} \\
\hline & & 0.5 & 1.0 & 1.5 & 2.0 & 2.5 & 3.0 & 3.5 & 4.0 & 4.5 & 5.0 & 5.5 & 6.0 & 6.5 & 7.0 & 7.5 & 8.0 \\
\hline 0.20 & 10 & 0.00 & 0.00 & 0.00 & 0.00 & 0.00 & 0.00 & 0.00 & 0.00 & 0.00 & 0.00 & 0.00 & 0.00 & 0.00 & 0.00 & 0.00 & 0.00 \\
\hline 0.40 & 84 & 0.00 & 0.00 & 0.00 & 0.00 & 0.00 & 0.00 & 0.00 & 0.00 & 0.00 & 0.00 & 0.00 & 0.00 & 0.00 & 0.00 & 0.00 & 0.00 \\
\hline 0.60 & 283 & 0.01 & 0.01 & 0.01 & 0.01 & 0.01 & 0.01 & 0.01 & 0.01 & 0.01 & 0.01 & 0.01 & 0.01 & 0.01 & 0.01 & 0.01 & 0.01 \\
\hline 0.80 & 670 & 0.01 & 0.01 & 0.01 & 0.01 & 0.01 & 0.01 & 0.01 & 0.01 & 0.01 & 0.01 & 0.01 & 0.01 & 0.05 & 0.05 & 0.05 & 0.05 \\
\hline 1.00 & 1308 & 0.01 & 0.01 & 0.01 & 0.01 & 0.01 & 0.01 & 0.01 & 0.01 & 0.01 & 0.05 & 0.05 & 0.05 & 0.05 & 0.26 & 0.26 & 0.26 \\
\hline 1.20 & 2261 & 0.01 & 0.01 & 0.01 & 0.01 & 0.01 & 0.01 & 0.01 & 0.06 & 0.06 & 0.30 & 0.30 & 0.30 & 0.30 & 0.30 & 0.30 & 0.30 \\
\hline 1.40 & 3590 & 0.01 & 0.01 & 0.01 & 0.01 & 0.01 & 0.07 & 0.07 & 0.34 & 0.34 & 0.34 & 0.34 & 0.34 & 0.34 & 0.34 & 0.34 & 0.34 \\
\hline 1.60 & 5359 & 0.01 & 0.01 & 0.01 & 0.01 & 0.07 & 0.07 & 0.37 & 0.37 & 0.37 & 0.37 & 0.37 & 0.37 & 0.37 & 0.37 & 0.37 & 0.37 \\
\hline 1.80 & 7630 & 0.01 & 0.01 & 0.01 & 0.08 & 0.08 & 0.41 & 0.41 & 0.41 & 0.41 & 0.41 & 0.41 & 0.41 & 0.41 & 0.41 & 0.41 & 0.41 \\
\hline 2.00 & 10467 & 0.01 & 0.01 & 0.01 & 0.09 & 0.45 & 0.45 & 0.45 & 0.45 & 0.45 & 0.45 & 0.45 & 0.45 & 0.45 & 0.45 & 0.45 & 0.45 \\
\hline 2.20 & 13931 & 0.01 & 0.01 & 0.09 & 0.09 & 0.49 & 0.49 & 0.49 & 0.49 & 0.49 & 0.49 & 0.49 & 0.49 & 0.49 & 0.49 & 0.49 & 0.49 \\
\hline 2.40 & 18086 & 0.01 & 0.01 & 0.10 & 0.52 & 0.52 & 0.52 & 0.52 & 0.52 & 0.52 & 0.52 & 0.52 & 0.52 & 0.52 & 0.52 & 0.52 & 0.52 \\
\hline 2.60 & 22995 & 0.01 & 0.01 & 0.11 & 0.56 & 0.56 & 0.56 & 0.56 & 0.56 & 0.56 & 0.56 & 0.56 & 0.56 & 0.56 & 0.56 & 0.56 & 0.56 \\
\hline 2.80 & 28721 & 0.01 & 0.11 & 0.60 & 0.60 & 0.60 & 0.60 & 0.60 & 0.60 & 0.60 & 0.60 & 0.60 & 0.60 & 0.60 & 0.60 & 0.60 & 0.60 \\
\hline 3.00 & 35325 & 0.01 & 0.12 & 0.64 & 0.64 & 0.64 & 0.64 & 0.64 & 0.64 & 0.64 & 0.64 & 0.64 & 0.64 & 0.64 & 0.64 & 0.64 & 0.64 \\
\hline 3.20 & 42871 & 0.01 & 0.13 & 0.67 & 0.67 & 0.67 & 0.67 & 0.67 & 0.67 & 0.67 & 0.67 & 0.67 & 0.67 & 0.67 & 0.67 & 0.67 & 0.67 \\
\hline 3.40 & 51423 & 0.01 & 0.13 & 0.71 & 0.71 & 0.71 & 0.71 & 0.71 & 0.71 & 0.71 & 0.71 & 0.71 & 0.71 & 0.71 & 0.71 & 0.71 & 0.71 \\
\hline 3.60 & 61042 & 0.01 & 0.75 & 0.75 & 0.75 & 0.75 & 0.75 & 0.75 & 0.75 & 0.75 & 0.75 & 0.75 & 0.75 & 0.75 & 0.75 & 0.75 & 0.75 \\
\hline 3.80 & 71791 & 0.01 & 0.79 & 0.79 & 0.79 & 0.79 & 0.79 & 0.79 & 0.79 & 0.79 & 0.79 & 0.79 & 0.79 & 0.79 & 0.79 & 0.79 & 0.79 \\
\hline 4.00 & 83733 & 0.01 & 0.82 & 0.82 & 0.82 & 0.82 & 0.82 & 0.82 & 0.82 & 0.82 & 0.82 & 0.82 & 0.82 & 0.82 & 0.82 & 0.82 & 0.82 \\
\hline 4.20 & 96932 & 0.01 & 0.86 & 0.86 & 0.86 & 0.86 & 0.86 & 0.86 & 0.86 & 0.86 & 0.86 & 0.86 & 0.86 & 0.86 & 0.86 & 0.86 & 0.86 \\
\hline 4.40 & 111449 & 0.01 & 0.90 & 0.90 & 0.90 & 0.90 & 0.90 & 0.90 & 0.90 & 0.90 & 0.90 & 0.90 & 0.90 & 0.90 & 0.90 & 0.90 & 0.90 \\
\hline 4.60 & 127348 & 0.17 & 0.94 & 0.94 & 0.94 & 0.94 & 0.94 & 0.94 & 0.94 & 0.94 & 0.94 & 0.94 & 0.94 & 0.94 & 0.94 & 0.94 & 0.94 \\
\hline
\end{tabular}

The colours indicate the most unfavourable potential damage: Green: no damage, Yellow: non-structural damage, Orange: local structural damage or partial collapse, Red: extensive or total collapse.

Table 3. Damage levels for the fragility curves.

\begin{tabular}{ll}
\hline $\begin{array}{l}\text { Damage } \\
\text { Level }\end{array}$ & Damage description \\
\hline $\begin{array}{l}\text { Low } \\
\text { Moderate }\end{array}$ & $\begin{array}{l}\text { Non-structural (for impact on a wall) } \\
\text { Local structural (for impact and damage of } \\
\text { one central column) }\end{array}$ \\
High & $\begin{array}{l}\text { Partial collapse (for impact and damage of } \\
\text { one lateral column) }\end{array}$ \\
Very high & $\begin{array}{l}\text { Extensive or total collapse (for impact and damage } \\
\text { of two or more lateral or central columns). }\end{array}$ \\
\hline
\end{tabular}

when the risk for an individual building must be evaluated for an owner or an insurance company, or for areas developed with a limited number of buildings mainly situated at the first line next to the slope, as for example in the case of Santa Coloma in Andorra (Corominas, 2005) where a small number of typologies should be analyzed.

The application presented in this paper was realized for a range of block sizes (from 0.2 to $4.6 \mathrm{~m}$ in diameter) and velocities (from 0.5 to $8 \mathrm{~m} / \mathrm{s}$ ), allowing a certain degree of generalization. The step-by-step methodology presented at Mavrouli and Corominas (2010) as well as the one proposed in this paper, is not limited to a simple theoretical casestudy. The methodology is flexible. It includes independent sub-procedures, which can be adapted to the building charac- teristics. In that respect, different geometries and structural grids can be analysed.

The development of class representative fragility curves, based on the statistical elaboration of the results for individual buildings at a zone (considering uncertainties in geometric dimensions, material properties...) is an approach that has been already followed in the domain of seismic vulnerability (Polese et al., 2008) and similar methods may be developed for the generalisation of the results.

In some cases of rock impacts on buildings, the dissipative capability of non-structural elements such as infill walls, furniture and other obstacles may act protectively for the building. On the side of safety, this relieving effect is not taken into account here.

\section{Appendix A}

\section{List of symbols}

$C: \quad$ value of the building

$d: \quad$ rock diameter

DI: damage index

$E_{k}: \quad$ kinetic energy

$l_{\mathrm{c}}: \quad$ column width

$l_{\mathrm{w}}$ : wall width

$m$ : block mass 


\begin{tabular}{|c|c|}
\hline$P_{\mathrm{e}, k}:$ & $\begin{array}{l}\text { encounter probability of a } \\
\text { rock with a possible } \\
\text { structural and non-structural } \\
\text { element of the building } \\
\text { " } k \text { " that may be struck } \\
\text { by a rock block of magnitude " } i \text { " }\end{array}$ \\
\hline$P_{\mathrm{ec}}:$ & $\begin{array}{l}\text { encounter probability of } \\
\text { a rock block with any column }\end{array}$ \\
\hline$P_{\text {ecc }}:$ & $\begin{array}{l}\text { encounter probability } \\
\text { of a rock with a central } \\
\text { column (for the example) }\end{array}$ \\
\hline$P_{\text {elc }}:$ & $\begin{array}{l}\text { encounter probability of } \\
\text { a rock with a lateral } \\
\text { column (for the example) }\end{array}$ \\
\hline$P_{\text {ew }}:$ & $\begin{array}{l}\text { encounter probability of } \\
\text { a rock with a wall } \\
\text { only (for the example) }\end{array}$ \\
\hline$P\left(E_{j}: R_{i}\right)$ & $\begin{array}{l}\text { probability of a } \\
\text { rockfall with a kinetic } \\
\text { energy (intensity) reaching the } \\
\text { critical section that marks } \\
\text { the developed area. The } \\
\text { latter is calculated as a } \\
\text { function of the magnitude (volume) } \\
\text { " } i \text { " and the velocity " } j " \\
P\left(R_{i}\right) \text { : annual probability of } \\
\text { occurrence of a rockfall } \\
\text { with a magnitude " } i "\end{array}$ \\
\hline$P(S: T):$ & $\begin{array}{l}\text { probability of the building } \\
\text { being on the block's trajectory }\end{array}$ \\
\hline RC: & reinforced concrete \\
\hline RRC: & relative recovery cost \\
\hline $\mathrm{RRC}_{\mathrm{cc}}:$ & $\begin{array}{l}\text { relative repair cost } \\
\text { for impact on a central } \\
\text { column (for the example) }\end{array}$ \\
\hline $\mathrm{RRC}_{\mathrm{lc}}:$ & $\begin{array}{l}\text { relative repair cost } \\
\text { for impact on a lateral } \\
\text { column (for the example) }\end{array}$ \\
\hline $\mathrm{RRC}_{\mathrm{w}}$ : & $\begin{array}{l}\text { relative repair cost } \\
\text { for impact on a wall } \\
\text { (for the example) }\end{array}$ \\
\hline$R(P):$ & $\begin{array}{l}\text { expected annual loss to } \\
\text { the property due to rockfall } \\
\text { (e.g. } € / y r)(\text { Fell, 2005) }\end{array}$ \\
\hline$v:$ & rock velocity \\
\hline$V\left(R_{i j}\right):$ & $\begin{array}{l}\text { vulnerability of the } \\
\text { building for a rockfall } \\
\text { of magnitude " } i \text { " and velocity " } j \text { " }\end{array}$ \\
\hline
\end{tabular}

Acknowledgements. This work has been performed within the framework of the "Mountain Risks" Marie Curie Research Training Network, funded by the European Union (6th Framework Program) contract number MRTN-CT-2006-035798. Partial support has been received also from the projects Safeland, funded by the European Union (7th Framework Program) grant agreement 226479 and Big Risk, funded by the Spanish Ministry of Science and Innovation, contract number BIA2008-06614.

Edited by: A. Günther

Reviewed by: F. Agliardi and another anonymous referee

\section{References}

Agliardi, F., Crosta, G. B., and Frattini, P.: Integrating rockfall risk assessment and countermeasure design by 3D modelling techniques, Nat. Hazards Earth Syst. Sci., 9, 1059-1073, doi:10.5194/nhess-9-1059-2009, 2009.

Allen, D. E. and Schrlever W. R.: Progressive collapse, abnormal loads and building codes, Proc.of ASCE National Meeting on Structural Engineering, Cleveland Ohio, 21-47, 1972.

Bell, R. and Glade, T.: Quantitative risk analysis for landslides - Examples from Bíldudalur, NW-Iceland, Nat. Hazards Earth Syst. Sci., 4, 117-131, doi:10.5194/nhess-4-117-2004, 2004.

Brauner, M., Weinmeistera, W., Agnera, P., Vospernikb, S., and Hoesle, B.: Forest management decision support for evaluating forest protection effects against rockfall, Forest Ecol. Manag., 207, 75-85, 2005.

Budetta, P.: Assessment of rockfall risk along roads, Nat. Hazards Earth Syst. Sci., 4, 71-81, doi:10.5194/nhess-4-71-2004, 2004.

Castleton, J.: Rock-fall hazards in Utah, USGS publications, PI-94, 2009.

Chau, K. T., Wong, R. H. C., and Wu, J. J.: Coefficient of restitution and rotational motions of rockfall impacts, Int. J. Rock. Mech. Min., 39, 69-77, 2002.

Corominas, J., Copons, R., Moya, J., Vilaplana, J. M., Altimir, J., and Amigó, J.: Quantitative assessment of the residual risk in a rock fall protected area, Landslides, 2, 343-357, 2005.

Dai, F. C, Lee, C. F., and Ngai, Y. Y.: Landslide risk assessment and management: an overview, Eng. Geol., 64, 65-87, 2002.

Evans, S. G. and Hungr, O.: The assessment of rockfall hazard at the base of talus slopes, Can. Geotech. J., 30, 620-636, 1993.

Fell, R., Ho, K. K. S., Lacasse, S., and Leroi, E.: A framework for landslide risk assessment and management, International Conference on Landslide Risk Assessment and Management, Vancouver, BC, Canada, 2005.

FEMA 321: Public Assistance Policy Digest, Guidance No. 4511.61, 2008.

Glade, T.: Vulnerability assessment in landslide risk analysis, Die Erd., 134(2), 123-146, 2003.

Guzzetti, F., Reichenbach, P., and Ghigi, S.: Rockfall hazard and risk assessment along a transportation corridor in the Nera valley, Central Italy, Environ. Manage., 34(2), 191-208, 2004.

Heinimann, H. R.: Risikoanalyse bei gravitativen Naturgefahren Fallbeispiele und Daten, Umwelt-Materialen 107/I, Bern, 1999.

Li, Z. H., Huang, H. W., Xue, Y. D., and Yin, J.: Risk assessment of rockfall hazards on highways, Georisk, 3(3), 147-154, 2009.

Mavrouli, O. and Corominas, J.: Vulnerability of simple reinforced concrete buildings in front of the rockfall impact, Landslides, 
7(2), 169-180, 2010.

Pierson, L. A, Davis, S. A., and Van Vickle, R.: Rockfall hazard rating system implementation manual. Federal Highway Administration (FHWA), Report FHWAOR-EG-90-01, FHWA, US Department of Transportation, 1990.

Polese, M., Verderame, G. M., Mariniello, C., Iervolino, I., and Manfredi, G.: Vulnerability curves for gravity load designed RC buildings in Naples - Italy, J. Earthq. Eng., 12(S2), 234-245, 2007.

Roberds, W. J.: Estimating temporal and spatial variability and vulnerability, in: Landslide risk management, edited by: Hungr, O., Fell, R., Couture, R., and Eberhardt, E., Proceedings of the International Conference on Landslide Risk Management, Vancouver, 31 May-3 June 2005, Taylor \& Francis, London, 129-157, 2005.

Romana, M.: Clasificación de los Taludes y Laderas Inestables en Roca en Función de sus Dimensiones, Proc. of "Simposio de taludes”, Barcelona, Spain, 2, 968-979, 2009.
Sezen, H.: Shear deformation model for reinforced concrete columns, Struct. Eng. Mech., 28(1), 39-52, 2008.

UNDRO: Mitigation Natural Disasters: Phenomena, Effects, and Options, Office of the United Nations, Disaster Relief Coordinator, Geneva, 1991.

Uzielli, M., Nadim, F., Lacasse, S., and Kaynia, A. M.: A conceptual framework for quantitative estimation of physical vulnerability to landslides, Eng. Geol., 102, 251-256, 2008.

Whitman, R. V., Reed, J. W. Y., and Hong, S. T.: Earthquake damage probability matrices, Proc. of the Fifth World Conference on Earthquake Engineering, Roma, 1973.

Wieczorek, G. F. and Snyder, J. B.: Historical rock falls in Yosemite National Park, US Geol. Surv. Open-File Report 03491, http://pubs.usgs.gov/of/2003/of03-491/of03-491.pdf (last access: September 2010), 2004. 